\title{
Observations on the biology of Spelaeiacris tabulae Peringuey (Orthoptera, Rhaphidophoridae), from the Wynberg cave (Capetown, South Africa)
}

\section{Gianmaria Carchini *, Claudio Di Russo * and Mauro Rampini **}

\section{SUMMARY}

Data on the age structure, fecundity, egg morphology and feeding habits of the Spelaeiacris tabulae population from Wynberg cave are reported and compared with other Rhaphidophoridae species. $S$. tabulae shows a certain degree of adaptation to cave life, as usual in the other temperate species of Rhaphidophoridae

\section{INTRODUCTION}

In the whole of Africa the Rhaphidophoridae are represented only by the endemic Macropathinae species: Spelaeiacris tabulae Peringuey, 1916 which, as far as we known, is only found in some sandstone caves in the Cape Peninsula. This species is a clear example of Gondwanian relict, because its closest relatives are now present in Patagonia and in the Australian region, showing a clear circum-antartic distribution (Karny, 1931).

Few studies on this species are known, (Peringuey, 1916; Karny, 1929; Hesse, 1929; Grindley, 1956) and at this time there is a scarcity of information on the biology and ecology of this species. In this paper we report the observations carried out in the cave and in

* Dipartimento di Biologia, Università Tor Vergata, Via O. Raimondo, 00173 Roma, Italy.

** Dipartimento di Biologia Animale e dell'Uomo, Università La Sapienza, Viale dell'Università 32, 00185 Roma, Italy 
laboratory on some ecological and morphological traits of this cave cricket.

\section{STUDY AREA AND METHODS}

The crickets were collected in the Wynberg cave (Table Mountain, Cape Province, South Africa, $900 \mathrm{~m}$ a.s.l.). The cave is located in a mediterranean climate area which is usually dry and hot during the summer. However, during the winter, a part of the cave is flooded (T. Hall, pers. communication). The fauna of the cave is known and includes spiders, isopods and beetles (Craven, in press). Even though the cave was visited by us during summer 1991, the external and internal temperatures of the cave, recorded during the visit, was $12^{\circ} \mathrm{C}$ and $10^{\circ} \mathrm{C}$ respectively, and the cave showed noticeable drip both from ceiling and walls.

Forty one specimens of Spelaeiacris tabulae were collected in the cave, $50 \mathrm{~m}$ from the entrance (G. Carchini, M. Di Domenico and T. Hall leg., 17.02.91). The crickets were mainly observed on the floor and the walls of the cave, where spiders and some isolated bats' and rodents' faecal pellets were also observed. The crickets were captured by hand and kept in a plastic container during the transport out of the cave.

We observed that most of the crickets died during the first hours after capture, when they were all together in the plastic box. In particular, several specimens showed torn off legs. So, each survivor was transferred into a separate box and in this way was transported to Italy without further deaths. The specimens were preserved in alcohol $75 \%$.

To describe the age structure of the cricket population, the metatibial length and pronotum length were recorded from 20 and 30 individuals respectively. The first measure was taken using a vernier caliper, the second using a stereo-microscope with a micrometric eyepiece. In both cases the measurements were to the nearest $0.05 \mathrm{~mm}$. As well as measuring them, we distinguished the nymphs from the adults by the morphology of sexual appendages in the males and by shape and color of the ovipositor in the females (see Fig. 1).

From the dissection of five individuals it was possible to collect five faecal pellets. The faecal pellets were spread on a slide $18 \times 18$ 


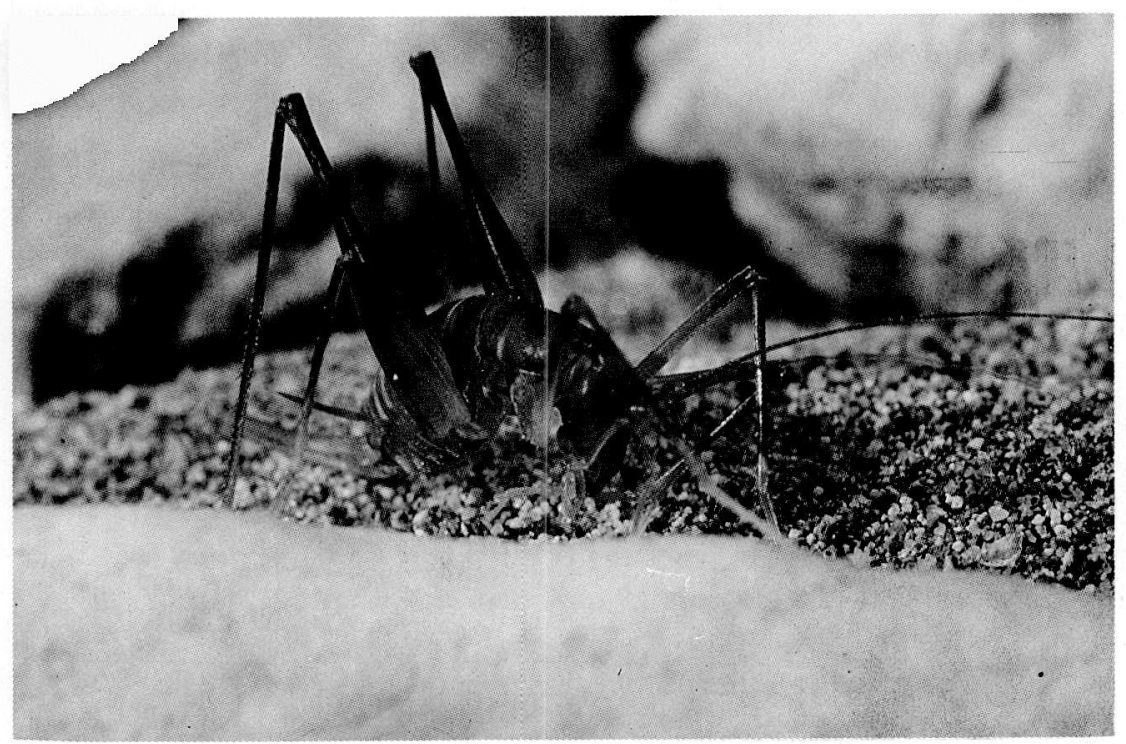

Fig. 1 - Adult female of Spelaeiacris tabulae

$\mathrm{mm}$ and examined through an optical microscope.

Also, from the dissection of three females, 8 mature eggs were isolated. The eggs were measured by stereo-microscope, and, after drying and sputtering, were observed also by S.E.M.

\section{RESULTS AND DISCUSSION}

\section{Age structure}

Both nymphs and adults were present in the sample. The adult size of the metatibia and pronotum ranges from 14.0 to $15.20 \mathrm{~mm}$ and from 3.08 to $3.52 \mathrm{~mm}$ respectively. In Fig. 2, the distributions of metatibial and pronotum lengths are reported. This analysis shows a wide distribution of age due to the presence of young and old nymphs together with adults. This large age variation in a single sample may be explained by continuous reproduction, without seasonal timing such as already suggested by Grindley (1956) from the presence of young nymphs throughout the year. This continuous breeding habit is peculiar to life cycles of tropical species (Masaki 

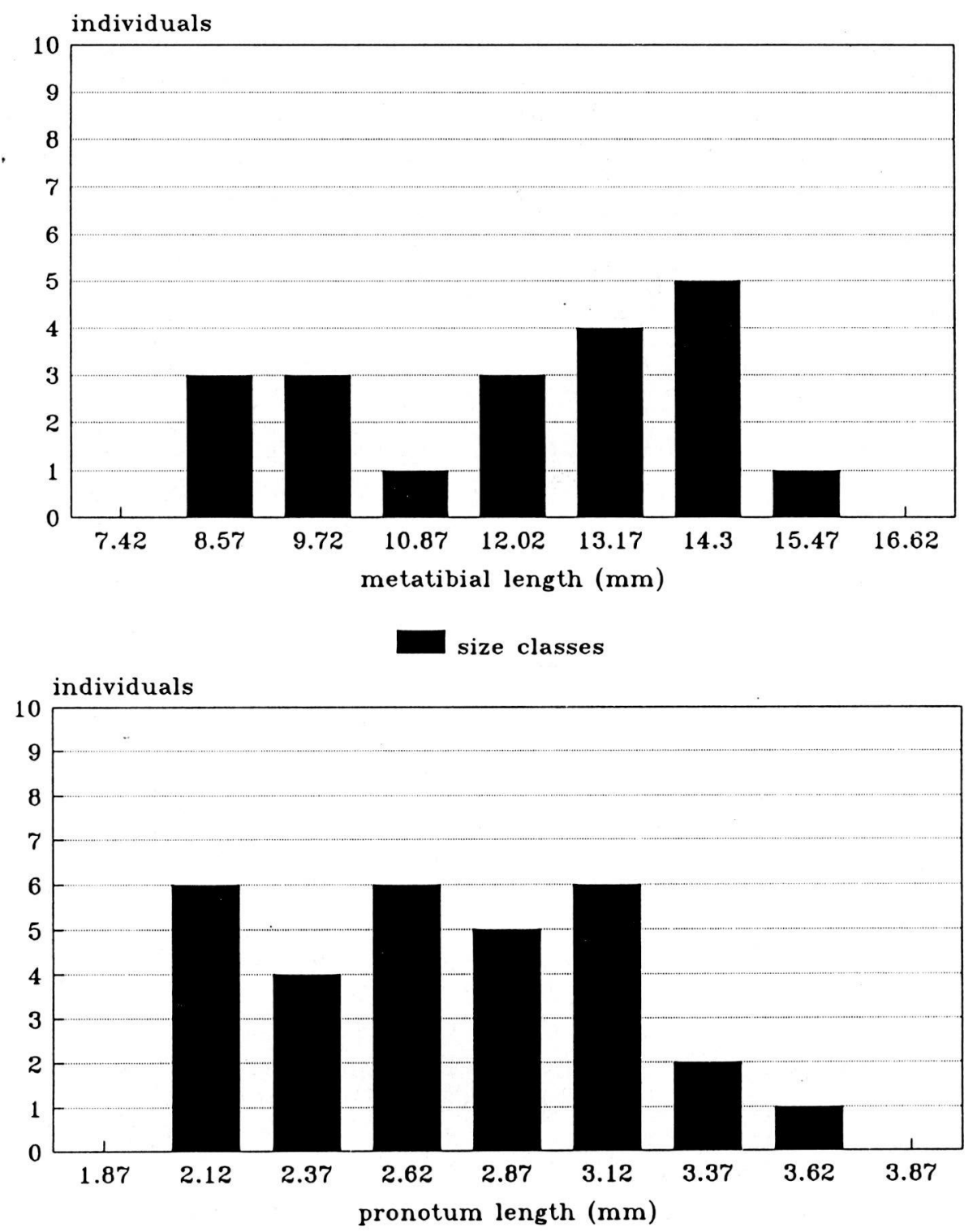

size classes

Fig. 2 - Age structure of $S$. tabulae population from Wynberg cave. Size frequency histograms are based on metatibial and pronotum lengths. The values reported on abscissa are the central values of the size classes. 
and Walker, 1987) and also to temperate populations and species adapted to the cave habitat (Culver, 1982; Carchini et al., 1991).

On the contrary, the life cycles in temperate epigean crickets are strongly affected by seasonality (Alexander, 1968; Masaki and Walker, 1987) and usually show little age variation between individuals in a sample. Since the climate at the Cape Peninsula is tipically temperate, the observed age structure appears to reflect an adaptation to cave life.

\section{Eggs}

The eggs of S. tabulae are cylindrical and slightly curved (Fig. 3). The measurements of the 8 eggs, made by optical stereo-microscope, range from 3.20 to $3.36 \mathrm{~mm}$ in length and from 1.20 to $1.25 \mathrm{~mm}$ in width. Because of damage during the preparation, we were only able to observe two eggs by S.E.M., so the following description is not complete. In particular we were not able to locate the micropiles.
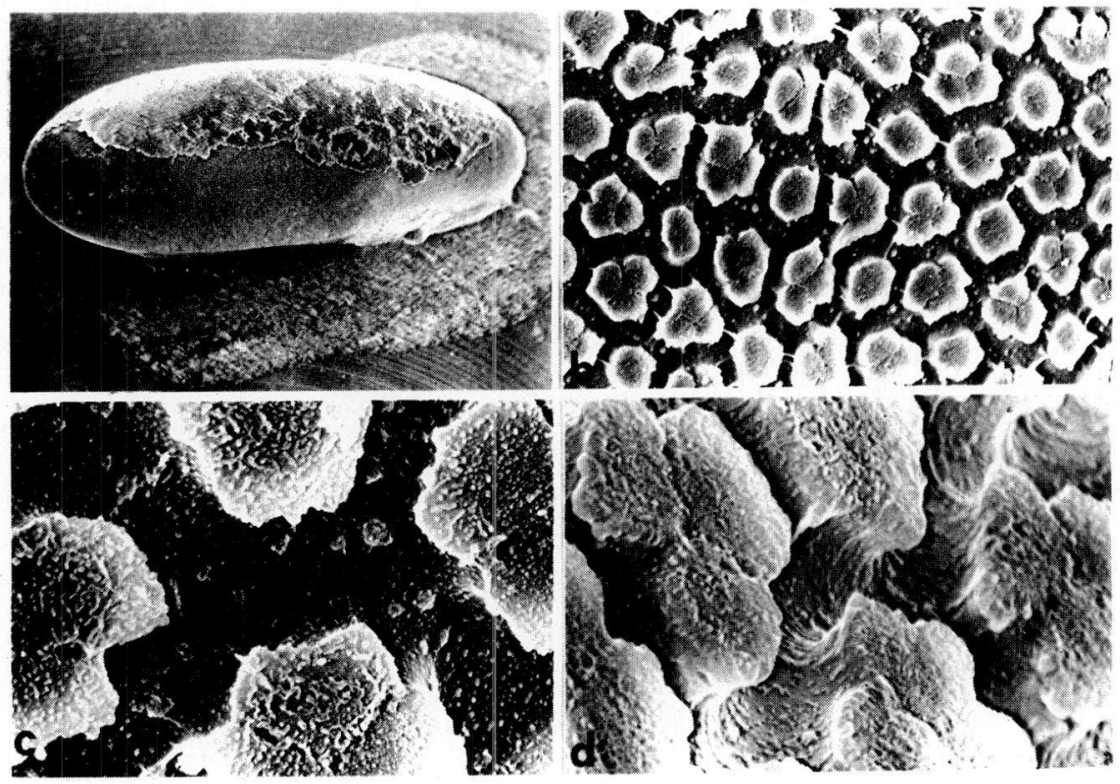

Fig. 3 - Morphology of S. tabulae eggs: a, entire egg (X 36). b, corion surface (X 1000). $\mathrm{c}$ and $\mathrm{d}$, particulars of surface sculptures showing the canals among the polygonal plates (X 4500). 
The corion shows an external surface without cristae, and regularly arranged in polygonal plates separated from each other by canals about 3 nanometer wide. The entire egg surface shows the same pattern. We did not find respiratory orifices either in the plates or in the canals. This fact seems to indicate the absence of specialized respiratory areas.

The general shape of $S$. tabulae egg is similar to those of the other Rhaphidophoridae species, but really this shape is very common in several Orthoptera (Uvarov, 1966; Hinton, 1981). On the contrary, the fine structure of the egg surface appears to be quite different from that shown in other Rhaphidophoridae. Particularly in the Dolichopodinae and Rhaphidophorinae species the egg surface shows a net of hexagonal cells, divided by emerging cristae (Rampini and Saltini, 1988).

Other differences may be observed in the number and in the relative size of the eggs. In Table 1 the number of eggs and the ratio between the egg length and body length of some Rhaphidophoridae species are reported. From these observations it appears that Spelaeiacris tabulae produce a small number of eggs, and, by comparing the ratio egg length/body length, it results that it produce

Table 1 - Comparison among egg and body size in several Rhaphidophoridae species. $\mathrm{N}$, average number of eggs for female found in the ovary or $\left(^{*}\right)$ layed. All measurements in mm.

\begin{tabular}{lcccccc}
\hline Species & $\begin{array}{c}\mathrm{N} \\
\text { (mean) }\end{array}$ & $\begin{array}{c}\text { egg } \\
\text { length }\end{array}$ & $\begin{array}{c}\text { body } \\
\text { length }\end{array}$ & $\begin{array}{c}\text { egg/ } \\
\text { body }\end{array}$ & Habitat & Authors \\
\hline $\begin{array}{l}\text { Spelaeiacris } \\
\text { tabulae }\end{array}$ & 2.66 & 3.30 & 10.5 & .314 & cave & - \\
$\begin{array}{l}\text { Dolichopoda } \\
\text { laetitiae }\end{array}$ & 12.50 & 4.10 & 21.0 & .195 & cave & 1 \\
$\begin{array}{l}\text { Hadenoecus } \\
\text { subterraneus } \\
\begin{array}{l}\text { Tachycines } \\
\text { asynamorus }\end{array}\end{array}$ & 7.24 & 4.00 & 17.5 & .23 & $\begin{array}{c}\text { cave } \\
\text { tropical } \\
\text { forest }\end{array}$ & 2 \\
\hline
\end{tabular}

(1): Ziccardi, unp. data; (2): Hubbel \& Norton, 1978; (3): Sampò \& Casale, 1978. 
larger eggs than other known Rhaphidophoridae. As in other cave adapted organisms, this feature could be assumed to represent an adaptation to cave life (see Culver, 1982). However, more data on the fecundity will be necessary to confirm this hypothesis.

\section{Feeding habits}

Hesse (1929) suggested that $S$. tabulae might feed on Lecanora lichens. This supposition was criticized by Grindley (1956) that has not been successful in trying to feed $S$. tabulae on fungi. In our observation, the faecal content showed the presence of six morphologically distinguishable types of items. We have found a total of 385 items in the pellets, including arthropod cuticle (7\%), lepidoptera scales $(40 \%)$, bat hairs $(15 \%)$, rodent hairs $(18 \%)$, green vegetables (19\%), vegetable fibers (1\%). No lichen remains as hyphae or unicellular algae were found.

The occurrence of these categories indicates an omnivorous diet common to those of other Rhaphidophoridae (Remy, 1931; Richards, 1962; Hubbel and Norton, 1978). The presence of arthropods together with bat hairs and lepidoptera scales, commonly found on bat guano deposits, may indicate an origin of this food inside the cave. Because of the presence of vegetable items in the faecal pellets we should assume the occurrence of feeding migrations outside the cave, as is well known in other Rhaphidophoridae (Remy, 1931; Richards, 1962; Richards 1969; Hubbel and Norton, 1978; Di Russo et al., 1991). However, the origin of vegetable items in our case could also be explained by the presence of some plants in the boxes used to transport the crickets.

\section{CONCLUSION}

These preliminary observations have allowed us to obtain new information on the little-known biology of $S$. tabulae. Even if further studies on the life cycle, phenology and feeding habits are needed, these preliminary data seem to indicate a certain degree of adaptation of this species to the cave habitat. As far as the origin of this adaptation to the cave habitat, $S$. tabulae could fit well the "refuge" model (Jeannel, 1965) which assumes that the caves are 
colonized by geographically isolated populations, forced there by unfavourable ecological changes. In fact, the Cape area is now isolated from the main part of the continent by a large barrier of aridity and the climate of the southern part of Africa, changed from wet and cold to arid and hot conditions during the last million years (Leleup, 1956; Darlington, 1968). This situation seem to favour persistence of hygrophilic organisms only in wet refuges as the caves of the Table Mountain area.

\section{ACKNOWLEDGMENTS}

We are grateful to Dr. S.A. Craven, Hon. Chairman of South African Speleological Association, Prof. J. R. Grindley and Mr. T. Hall for their friendly collaboration and help in cricket collecting. We also thank Mr. L. De Pasquale for the faecal content analysis.

\section{REFERENCES}

ALEXANDER, R.D. 1968. Life cycle origins, speciation, and related phenomena in crickets. Quart. Rev. Biol. 43: 1-41.

CARCHINI, G., C. DI RUSSO, and V. SBORDONI. 1991. Contrasting age structures in cave cricket populations: patterns and significance. Ecol. Entomol. 16: 305-314.

CRAVEN, S.A. (in press). A history and review of biospeology in the Cape province of South Africa. Mem. Biospeol.

CULVER, D.C. 1982. Cave life. Evolution and Ecology. Harvard University Press.

DARLINGTON, P.J. 1968. Biogeography of the Southern End of the world. Mc Graw-Hill Book Company.

DI RUSSO, C., L. DE PASQUALE, G. CARCHINI, and V. SBORDONI. 1991. Preliminary data on the feeding habit of Dolichopoda (Orth. Rhaphidophoridae) by means of faecal content analysis. Mem. Biospeol. 18: 81-84.

GRINDLEY, J.R. 1956. The cave locust Spelaeiacris tabulae Per. Bull. S. Afr. Speleol. Ass. 2: 9-10.

HESSE, A.J. 1929. Appendix to Spelaeiacris tabulae Per. Ann. S. Afr. Mus. 29: 273-275.

HINTON, H.E. 1981. Biology of Insect eggs. Pergamon press. Oxford.

HUBBEL, T.H. and R.M. NORTON. 1978. The systematics and biology of the cave crickets of the North American tribe Hadenoecinae (Orth. Salt.: Rhaph.: Dolichopodinae). Miscellaneous Publications Museum of Zoology, University of Michigan, 156: 1-124.

KARNY, H.H. 1929. A revision of the South African Gryllacridae (Orthoptera Saltatoria). Ann. S. Afr. Mus. 29 (1): 77-151.

KARNY, H.H. 1931. On the geographical distribution of the Indo-African and Mediterranean Gryllacrids. Trans. Roy. Soc. S. Afr. 19: 99-105.

JEANNEL, R. 1965. La genèse du peuplement des milieux souterrrains. Rev. Ecol. Biol. Sol. 2: 1-22.

LELEUP, N. 1956. La faune cavernicole du Congo belge et considerations sur le Coléoptères reliques d'Afrique intertropicale. Ann. Mus. R. Congo belge Sc. Zool. 46: 9-171.

MASAKI, S. and T.H. WALKER. 1987. Cricket life cycles. In M.K. Hecth, B. Wallace and G.T. Prance (eds.). Evol. Biol. 21: 349-423. 
PERINGUEY, L. 1916. Descriptions of new or little-known Orthoptera in the collection of the South African Museum. Ann. S. Afr. Mus. 15 (5): 401-452.

RAMPINI, M. and G. SALTINI. 1988. Osservazioni preliminari sulla ultrastruttura delle uova degli Ortotteri Rafidoforidi. LII Congr. Naz. U.Z.I., Camerino: 71.

REMY, M.P. 1931. Observations sur les moeurs de quelques orthoptères cavernicoles. Annal. Sc. Nat., Zoologie, 14: 263-274.

RICHARDS, A.M. 1962. Feeding behaviour and enemies of Rhaphidophoridae (Orthoptera) from Waitomo cave, New Zealand. Trans. Roy. soc. N.Z., 2 (15): 121-129.

RICHARDS, A.M. 1969. Observations on the biology of Pallidotettix nullarborensis Richards (Rhaphidophoridae: Orthoptera) from the Nullarbor plain. Proc. Linn. Soc. N.S. Wales, 94: 195-206.

SAMPÒ, A. and A. CASALE. 1978. Osservazioni sulla locusta delle serre Tachycines asynamorus Adelung (Orthoptera Rhaphidophoridae). Atti Giornate Fitopatologiche, Bologna: 307-312.

UVAROV, B.P. 1966. Grasshopper and Locust. A handbook of general Acridology. Vol. 1. Cambridge University Press. 